to be used in every working cylinder. In long voyages, this oil in the aggregate, amounts to a large quantity, and some means are absolutely necessary to get rid of it. Will not the mixture of nil with the easily vaporized liquid change in some way its nature? I hope that Mr. Du 'Trembley has accomplished all he states, and that his engine will prove something more than a model.

Fulton.

For the Journal of the Franklin Institute.

Passage of the Steamer Baltic from Liverpool.

The Quickest Trip on Record, has been made by the steamer Baltic of the Collins line of steamers. She left Liverpool at 4 o'clock P. M., on Wednesday the 6th of August, and passed the battery at New York, at 20 minutes past 6 , on Saturday morning the 16 th. Apparent time 9 days, 14 hours, 20 minutes. Actual time 9 days, 18 hours, 45 minutes. She had good weather and fair winds for the greater part of the passage, and her daily run was as follows:-

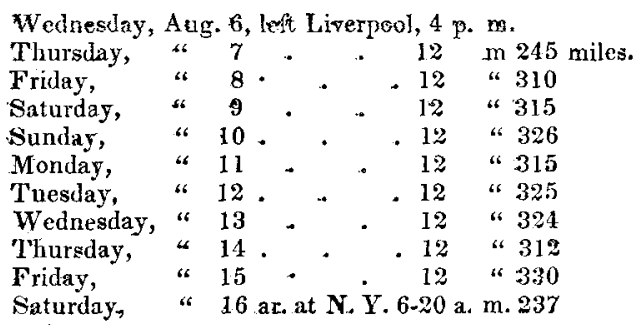

On the arrival of the Balice, the engineers of the Pacific presented to the engineers of the Baltic, the wreath of championship which they had received at the time they made their quick trip, it being well understood that the one who makes the quickest trip, is to have the custody of the said wreath, and is of course, by right, the champion of the line, to say nothing of the Cunard steamers, which are now allowed to arrive and lepart without note, so far as speed is concerned.

$\mathrm{H}$.

\title{
For the Journal of the Franklin Institute.
}

\section{Lake Steamer Buckeye State.}

This vessel, recently added to our lake fleet, has some peculiar features in her machinery, which render her worthy of special note. She has one of Smith \& Baird's compound expansion annular beam engines, being the first of the kind applied to any steamer in this or any country; the whole has been arranged by Erastus W. Smith, Esq., engineer, of New York City, and is a good specimen of engineering: The peculiar feature of this engine, is the employment of two cylinders, one being situated within the other, both having the same stroke of piston. 'The small cylinder has a diameter of 37 inehes, and a stroke of 11 feet, and into it the steam from the boiler of $40 \mathrm{lbs}$. average pressure is admitted, by a set of double balance valves, of the usual form. The larger cylinder surrounds the inner one, its diameter is 80 inches. The space between the two 
forms an annular chamber, and the large piston has two rods, and is facked on its inner and outer circumference, with this exception, the engine is of the usual form; but the adrantage of admitting steam of high pressure, full stroke, or nearly so, on to the piston of the small cylinder, and expanding it into the large cylinder, must be apparent, as the great shock caused by the admission of steam of high pressure on to the area of a large piston, is almost entirely got rid of, and the method of expansion is more efficient. 'The following are some of the dimensions of the Buckeye State:-

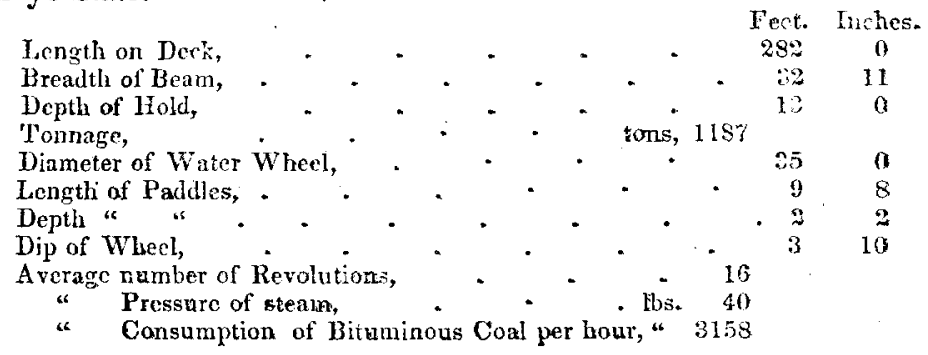

While the Mayflower, a boat of about the same size and speed, consumes $6160 \mathrm{lbs}$ per hour, showing a decided saving of fiel. She has three boilers with square fronts, 9 feet wide, and round shells 9 feet diameter, and in length 17 feet 9 inches. Fach boiler has but one furnace, 8 fect wide, with grates 6 feet 6 inches long, with two lower flues of 20 inches diameter, and one of 26 inches; the return to the chimney, which is in front, is through 190 iubes of 3 inches internal diameter, which tubes rise 4 inches at the front end; whole number of tubes 570; diameter of chimney $6 \frac{1}{5} \mathrm{ftet}$; height above grate, 65 feet; draft natural, and steam abundant; no trouble has yet been experienced from the great length of tube. It would be desirable to know the temperature in the chimney, as it is possible that the tubes may be longer than is necessary, as it has generally been supposed that very long tubes gave no additional evoporating power. This question is an important one, and I' shall have it examined into, and will report at some future time.

X.

\section{Recent Improvements in Photography. 'By Rozenr Huxr."}

With the advance of this beautiful art there appears to be a progressively increaing desire to produce more artistic results; and numeions manipulatory improvemeats have recently been introduced, many of them with the most decided advantage. It is thought desirable, therefore, to devote a short space to the deseription and consideration of such of these as are the most important.

The use of collodion promises to be of exceeding importance. Collodion is a peculiar preparation, formed by dissolving gun-cotton in ether; it is a very mola inous solution, of a volatile character, and the ether evaporating, leaves a film of the utmost transpartncy behind. It is not all kinds of g:m-cotton which dissolve equally well in ether; the most easily soluble is prepared by soaking good cotton in a saturated solution of nitrate of potash for some time: it is then, in a moist state, plunged into

- From the London Art Journal for July, 1851. 